\title{
Estratégias para Condução do Diálogo a Distância
}

\author{
Dialogue Strategies on Distance Education
}

\section{Sílvia Dotta}

Universidade Federal do ABC

Centro de Matemática, Computação e Cognição

silvia.dotta@ufabc.edu.br

\author{
Marcelo Giordan \\ Universidade de São Paulo \\ Faculdade de Educação \\ giordan@usp.br
}

\begin{abstract}
Resumo Este trabalho apresenta estratégias de comunicação escrita, a partir de uma concepção dialógica de Educação, que privilegia a co-participação de estudantes e tutores na trajetória de aprendizagem. Parte-se do pressuposto de que o tutor tem o papel de educador e é um dos sujeitos responsáveis pela formação de estudantes, uma vez que irá mediar a aprendizagem, estabelecendo um diálogo ao mesmo tempo acolhedor e instigador da problematização do conhecimento. A concepção de aprendizagem dialógica oferece subsídios para estabelecer as características da interação, selecionar a linguagem mais adequada para o diálogo escrito a distância, conquistar o engajamento do estudante para a problematização e levá-lo à aprendizagem autônoma. Discutem-se os estudos socioculturais desenvolvidos por Vigotski, Bakhtin, Wells, dentre outros, para investigar a interação dialógica como alternativa para o diálogo a distância. Sugere-se o uso da escrita sensivel, para estabelecer a empatia com estudantes, e do questionamento dialógico, para problematizar as dúvidas enviadas. Essas estratégias são analisadas à luz de uma experiência prática, na qual uma tutora instaurou um jogo de perguntas e respostas, e com isso, conseguiu, em alguns casos, o engajamento de estudantes, por meio do estabelecimento de empatia, do compartilhamento do processo de construção de ideias e da prevalência da função dialógica do discurso. Ao final, é proposta uma reflexão sobre a importância da autonomia do estudante em cursos a distância e como fomentar essa autonomia.
\end{abstract}

Palavras-Chave: Diálogo Virtual, Estratégias de Tutoria, Aprendizagem dialógica

\begin{abstract}
This paper presents strategies of written communication, from a dialogic conception of education, which focuses on co-participation between students and tutors in the learning development. It starts from the assumption that the tutor is an educator, and is responsible by students education, it will mediate learning, establishing a warm and instigator dialogue that deal through knowledge problematization. The concept of dialogic learning, developed in a research whose study object was a tutoring service, provides fundamentals to establish the characteristics of interaction, to select the apropriated language for distance dialogue, to get student engagement and autonomy. Sociocultural studies by Vygotsky, Bakhtin, Wells, among others, are introduced in order to investigate the dialogic interaction as an alternative to the distance dialogue. It is suggested the use of sensitive writing, to establish students empathy, and dialogic inquiry, to problematize questions. These strategies are analyzed in light of a practical experience, in which a tutor has established a questions and answers game, and with that, in some cases, got engagement of students, through the establishment of empathy, the sharing ideas construction process and the prevalence of the dialogic discourse function. Eventually, it is proposed a reflection on the importance of student autonomy in distance education and how to encourage that autonomy.
\end{abstract}

Keywords: Virtual Dialogue, Tutoring Strategies, Dialogic Learning

Recebido: 8 de Março de 2014 / Aceito: 17 Agosto de 2014

DOI: 10.5753/RBIE.2014.22.01.77 


\section{Introdução}

Um dos desafios enfrentados por tutores em Educação a Distância (EaD), mediada pela internet, é desenvolver estratégias eficazes para a condução do diálogo escrito por meio de ferramentas de comunicação síncrona ou assíncrona, como correio eletrônico, fórum, chat. Afora o necessário domínio técnico das ferramentas de comunicação, síncrona ou assíncrona, a escolha da linguagem apropriada, a postura a ser assumida pelo tutor, as estratégias de interação etc. são fatores cruciais para o processo de aprendizagem, na medida em que contribuem para garantir a qualidade da Educação. Este trabalho apresenta uma reflexão sobre estratégias de comunicação escrita, a partir de uma concepção dialógica de Educação, que privilegia a co-participação de estudantes e tutores na construção da trajetória de aprendizagem.

O princípio dessa reflexão considera o tutor um educador, pois ele é um dos sujeitos responsáveis pela formação de estudantes em um curso a distância, e irá mediar a aprendizagem, estabelecendo um diálogo ao mesmo tempo acolhedor e instigador da problematização do conhecimento. Como educador tem a tarefa de problematizar aos educandos o conteúdo que os mediatiza, e não a de dissertar sobre ele, de dá-lo, de estendê-lo, de entregá-lo, como se se tratasse de algo já feito, elaborado, acabado, terminado [13]. Nesse sentido, seu papel é de orientador, ele deve promover a realização de atividades, apoiar em sua resolução, oferecer novas fontes de informações e favorecer sua compreensão [17], suscitando o engajamento ativo do estudante na elaboração de suas respostas.

Muitos estudantes, ao se matricularem em cursos a distância, devido à sua frequência em cursos tradicionais, nos quais foram tratados como meros receptores, depósitos de informação, imaginam que esse modelo de educação instrucional irá se repetir a distância e são surpreendidos pela necessidade do diálogo. O tutor tem o papel de gestor da comunicação, cabe a ele desenvolver estratégias para se aproximar do estudante, retirá-lo do silêncio virtual, conduzindo-o a problematizar o conhecimento. Essa atitude pressupõe a apropriação, pelo tutor, de discursos dialógicos na formulação de suas mensagens, a prática da alteridade, o estabelecimento de empatia com o estudante, considerando seus conhecimentos prévios, entendendo suas necessidades e levando-o a construir suas próprias respostas.

A postura do tutor deve, então, ser dirigida para o trabalho em parceria com o estudante, orientando-o para o diálogo autônomo, o trabalho em projetos e a aprendizagem por pesquisa. Para isso, ele precisa converter-se em formulador de problemas, provocador de interrogações, coordenador de equipes de trabalho. Ele deixa de ser transmissor de informações e passa a ocupar o lugar de agenciador de comunicação, de uma comunicação fundamentada na interação [19].

Interação é entendida aqui não como uma característica do meio, mas um processo de construção da comunicação. Uma troca de comunicação só é interativa se cada uma das partes, emissor e receptor, pode responder à outra pela mesma forma. Isso significa que o emissor é um potencial receptor e o receptor, um potencial emissor. No papel de emissor, espera-se a participação do receptor, no sentido de que esse possa (deva) interferir na mensagem, articulando inúmeras possibilidades de significações, desconstruções e reconstruções. Portanto, interação é um continuum, uma variável, não apenas uma condição, e a maioria das comunicações, interpessoais ou não, pode ser mais ou menos interativa. Por suposto, quanto mais houver oportunidades de interação em um contexto educativo, mais bem-sucedido será o processo de aprendizagem.

Considerando o exposto, muitas questões podem ser formuladas: quais são as características da interação? Qual linguagem é mais adequada para o diálogo escrito a distância? Que estratégias podem ser adotadas para conquistar o engajamento do estudante para um diálogo problematizador? Que ferramentas estão disponíveis ao tutor para o cumprimento de sua tarefa? A concepção de aprendizagem dialógica, desenvolvida a partir de uma pesquisa que teve como objeto de estudo a oferta de um serviço de tutoria [10], oferece subsídios fundamentais para ajudar a responder a essas questões e para desenvolver estratégias para a condução do diálogo a distância. Suas bases teóricas são apresentadas no próximo item.

\section{Concepção dialógica de aprendiza- gem}

A perspectiva escolhida para o estudo do diálogo em EaD parte da construção teórica de Bakhtin [1, 2, 3] sobre o conceito de interação verbal que encara a enunciação individual como um fenômeno puramente sociológico. Bakhtin [2] sugere que o estudo fecundo do diálogo pressupõe uma investigação das formas usadas na citação do discurso, uma vez que essas formas refletem tendências básicas e constantes da recepção ativa do discurso de outrem, e é essa recepção que é fundamental para o diálogo [2: 146]. O autor inaugura o estudo da linguagem sob um ponto de vista dialético, cuja essência é o fenômeno social da interação verbal, e vê o diálogo como uma das formas mais importantes de interação verbal. Aqui, o diálogo tem um sentido amplo, não é apenas a comunicação em voz alta, de pessoas colocadas face a face, mas 
toda comunicação verbal, de qualquer tipo que seja [2: 123]. A comunicação verbal é sempre acompanhada por atos sociais de caráter não-verbal como gestos e expressões faciais. Ora, na comunicação a distância, utilizandose basicamente de trocas textuais, a escrita precisa ganhar novos símbolos que possam representar o elemento expressivo, a entonação, dos enunciados entre os interlocutores, dando conta de representar o sentido pleno daquilo que está sendo comunicado.

$\mathrm{O}$ ato da fala, a enunciação, é de natureza social [2, p. 109], pois é o produto de dois indivíduos socialmente organizados [2: 112]. Com isso, Bakhtin não estava se referindo somente à prática cotidiana do diálogo, mas, sim, ao dialogismo, o diálogo entre discursos, à construção do enunciado, interior ou exterior, falado ou escrito, em situação de conversas cotidianas ou de escritas científicas, de cartas pessoais ou legislações etc. Enunciar é dar vida à palavra, movê-la da posição de sinal para a de signo. A enunciação é a orientação da palavra por uma situação de mundo. O locutor seleciona a palavra, ou a oração, de um estoque social para dirigi-la a um interlocutor, um auditório, que pode ou não ser real. A palavra, como signo, é determinada pelas relações sociais, é orientada pelo contexto e por uma situação precisos, portanto, sempre pressupõe uma audiência socialmente organizada, com suas regras, costumes, repertórios. O signo linguístico adquire a sua identidade na relação dialética entre a estabilidade de sua significação que lhe permite ser reconhecido como o mesmo signo entre diferentes situações de enunciação, e a mobilidade que ele adquire relativamente à especificidade dessas situações enunciativas. A situação social mais imediata e o meio social mais amplo determinam completamente a estrutura da enunciação [2, p. 113]:

Bakhtin $[1,2]$ considera as enunciações as reais unidades da cadeia verbal, em outras palavras, o enunciado é a unidade da comunicação discursiva. Todo enunciado é um elo na cadeia da comunicação discursiva, e não pode ser separado dos elos precedentes que o determinam tanto de fora quanto de dentro, gerando nele atitudes responsivas diretas e ressonâncias dialógicas. [1: 300]. Cada enunciado particular é individual, mas cada campo de utilização da língua elabora seus tipos relativamente estáveis de enunciados, os gêneros do discurso [1: 262].

Os gêneros do discurso são caracterizados pelos contextos em que são utilizados: por exemplo, os dialetos sociais, o comportamento característico de grupo, os jargões profissionais, as linguagens genéricas, as linguagens de autoridades de vários círculos e de modas passageiras, as linguagens que servem a propósitos sociopolíticos etc. [1: 262]. A heterogeneidade dos gêneros do discurso é tanta quantas forem as possibilidades da atividade humana e irá variar em função da situação, da composição dos participantes da interação e do tema.

Segundo Bakhtin [1: 285], quanto melhor dominamos os gêneros tanto mais livremente os empregamos, tanto mais plena e nitidamente descobrimos neles a nossa individualidade, refletimos de modo mais flexível e sutil a situação singular da comunicação. O domínio de uma ampla diversidade de gêneros discursivos está relacionado ao acesso que o falante tem às diversas esferas sociais, profissionais, situacionais. A composição e estilo do enunciado também auxiliam a caracterizar seu gênero. $O$ primeiro elemento a determinar a composição e o estilo de um enunciado é o seu conteúdo semântico-objetal, a ideia do sujeito do discurso com relação ao objeto e ao sentido; o segundo é o elemento expressivo, a relação valorativa do falante com o objeto de seu discurso [1:289]. O tema é o sentido da enunciação completa, um sentido definido e único, uma significação unitária. O tema é individual e não-reiterável e apresenta-se como a expressão de uma situação histórica concreta. Esses conceitos são tão intrínsecos que não é possível delimitar claramente a fronteira entre eles, pois a significação é um aparato técnico para a realização do tema [2: 129], é ela que cria o elo entre os interlocutores para que ocorra a compreensão.

A compreensão é a apreensão do tema e é uma forma de diálogo, pois a uma dada enunciação faz-se corresponder uma resposta a ser elaborada pelo interlocutor. O falante espera a compreensão ativa responsiva, isto é, ele espera uma resposta do interlocutor, seja esta imediata ou posterior. A compreensão ativa responsiva é o objetivo real da comunicação discursiva, daí que todo enunciado é constituído não só por seu autor, como também por seu destinatário, isto é, um enunciado é sempre endereçado a alguém, seja um participante de um diálogo imediato, seja uma coletividade representante de algum campo da comunicação cultural, seja um público mais ou menos amplo, mais ou menos diferenciado. É a antecipação da atitude responsiva que determina a seleção que o falante fará de um ou outro gênero, composição e estilo do enunciado. Essa antecipação, contudo, é dependente do tipo de relação que o falante tem com seu destinatário.

A relação entre o texto e a audiência é o próprio diálogo, uma vez que não existe uma percepção passiva da mensagem [16]. Portanto, o destinatário é importante elemento constitutivo de uma enunciação. O discurso dialógico é percebido não apenas pela coincidência do código entre duas falas, mas pela presença de uma memória comum compartilhada entre o emissor e seu destinatário. Essa memória é contexto cultural, histórico e situacional do destinatário. A comunicação com um interlocutor somente é possível se houver alguma memória comum entre emissor e destinatário. O emissor constrói uma "imagem de sua audiência". Isso significa que todo texto contém 
um minissistema de todas as conexões da cadeia comunicativa e, assim como se pode abstrair do texto a posição do autor, pode-se reconstruir o leitor/receptor ideal [16: 83].

Bakhtin [1] afirma que a escolha das palavras no processo de construção de um enunciado é feita em outros enunciados, congêneres ao enunciado que o falante pretende construir. Cada enunciado é pleno de variadas atitudes responsivas a outros enunciados de dada esfera da comunicação discursiva [1: 297], aos quais respondemos, concordamos, polemizamos, ponderamos e acrescentamos nossa entonação expressiva. Isso significa que cada enunciado é povoado de enunciados anteriores, opiniões de interlocutores imediatos ou mesmo de visões de mundo, teorias. A atitude responsiva de um enunciado liga-o não só aos enunciados precedentes como também aos subseqüentes. São essas conexões que conferem aos enunciados o caráter dialógico.

As relações dialógicas de um enunciado são amplas, diversificadas, complexas, povoadas de diferentes vozes e consciências, portanto, polifônicas, que não necessariamente dos falantes/ouvintes em um diálogo ou de suas réplicas, mas podem ser distantes no tempo e espaço, anônimas, podendo ser impessoais e imperceptíveis. Bakhtin [3] destaca que o enfoque dialógico é possível a qualquer parte significante do enunciado, a uma palavra isolada, aos estilos de linguagem, aos dialetos sociais, ou à própria enunciação como um todo. Isso significa que o discurso dialógico não se limita a um fenômeno puramente linguístico, mas é essencialmente construído por relações dialógicas extralinguísticas. Então, o conceito de dialogismo forma-se a partir da noção de vozes que se enfrentam em um mesmo enunciado e que representam os diferentes elementos históricos, sociais e lingüísticos que atravessam a enunciação.

A forma como essas vozes entram em contato em um enunciado é um critério indispensável para a compreensão da estrutura composicional da enunciação [24]. Para Lotman [16], todo texto exerce uma dualidade funcional, a de transmitir adequadamente uma informação e a de gerar novos significados. A primeira função, chamada de unívoca, pressupõe um completo entendimento dos códigos utilizados entre os emissores e receptores. A segunda, chamada de dialógica, se dá pela heterogeneidade de seus elementos constitutivos, alguns dos quais formam "textos dentro de textos" [16: 377]. Ambas as funções estão presentes na maioria dos textos, entretanto, uma ou outra tende a prevalecer. Segundo Wertsch e Smolka [24: 136], nos gêneros de fala organizados em torno da função unívoca do texto, há pouco espaço para que a voz receptora questione, desafie ou, por outro lado, influencie a voz transmissora, enquanto que nos gêneros em que prevalece a função dialógica, cada voz tomará as enunciações das outras vozes como estratégias de pensamento. Quando um texto interage com consciências heterogêneas, novos significados são formados e isso resulta a sua reestruturação. Os significados são formados tanto pela interação entre diferentes estruturas semióticas como pelos complexos conflitos de significados entre o texto e seu contexto [16: 378]. A função dialógica do texto aponta o caminho para a compreensão da criação de significados, um processo que pode ocorrer tanto no plano de funcionamento intramental como no intermental [24: 134]. Por isso, essa função é vista como um dispositivo de pensamento, como criadora de novos significados.

A proposta de criação de estratégias de condução do diálogo em $\mathrm{EaD}$ abordada neste trabalho, considera a necessidade de se ter a dialogia presente nas trocas textuais, entre tutores e estudantes. A função dialógica é criadora de novos significados e a intensificação de seu uso na Educação pode conduzir os estudantes para o domínio de inúmeros dispositivos de pensamento. Para tanto, é essencial a atuação dos tutores no sentido de, por meio do discurso dialógico, influenciar a construção do conhecimento. Sob essa ótica, a abordagem de Wells [23], sobre o conceito de questionamento dialógico (dialogic inquiry), ao discorrer sobre a natureza de atividades educacionais que possam contribuir para a aprendizagem, aponta interessante caminho para o desenvolvimento de estratégias adequadas.

$\mathrm{O}$ conceito de questionamento dialógico (dialogic inquiry), segundo o qual o conhecimento é co-construído por professores e estudantes em atividades realizadas em parceria, por meio do debate e do discurso dialógico, sugere que a natureza dialógica do discurso deve ser explorada para possibilitar a construção colaborativa do conhecimento. Por meio do discurso dialógico, ideias podem ser refinadas e esclarecidas. Wells [23] sugere que os estudantes devem ser encorajados a expressar suas opiniões individuais e, também, a comentar e questionar as opiniões dos outros, pois esse processo poderá contribuir para o entendimento individual e coletivo. Para isso, é necessário considerar que o discurso deve envolver mais que uma simples troca de opiniões, mas que essa troca, questionamento e revisão de ideias levarão a um novo entendimento, a uma transformação, daquilo que se conhecia previamente [23: 112]. Mudança, ou transformação, isto é, melhorar ou superar o que se conhece, é o objetivo principal do processo de construção do conhecimento. Essa mudança se dá por uma melhoria, por parte dos estudantes, no processo de elaboração do discurso e, em conseqüência em seu entendimento sobre os tópicos e problemas abordados em sala de aula. É por meio da participação dos estudantes em atividades de construção de conhecimento - como, por exemplo, produzir e responder a enunciados, conversar sobre o que é "conhecido" e o que é "dito" - que os estudantes se apropriam dos 
gêneros do discurso e dos modos de saber que esses gêneros medeiam, e, dessa forma, transformam seu entendimento individual e coletivo sobre os objetos de conhecimento [23: 111].

Na prática, o autor sugere a criação de uma concepção dialógica de Educação, que toma como objeto de aprendizagem a evolução no entendimento do que é concebido, por meio da apropriação e exploração de recursos culturais como ferramentas para o engajamento em debates que levem à construção de significados individuais e sociais, e que têm implicações para além da sala de aula [23: 227).

Nesse contexto, o papel do professor é baseado em dois pressupostos: que a prática do ensino deve prover uma aprendizagem em direção a práticas semióticas valorizadas pelo contexto cultural, e que o ensino-aprendizagem envolve essencialmente uma relação dialógica. Entretanto, o diálogo entre professor e estudante, não é um diálogo entre iguais, por isso o professor ocupa um papel diferente do dos estudantes, o papel de mediador, e precisa assegurar que os estudantes sejam engajados aos conteúdos curriculares, e apropriar-se desses conteúdos para seu proveito próprio, atual e futuro, assim como possam tornar-se membros produtivos da sociedade da qual fazem parte. [23: 242]. Esse engajamento depende, sobretudo, da realização de atividades colaborativas por meio da criação, na sala de aula, de uma comunidade de aprendizagem, na qual, ocorre o compartilhamento de conhecimento entre professores e estudantes e entre estudantes e estudantes.

Essa concepção de Wells [23] fundamenta-se no conceito de zona de desenvolvimento proximal (zdp) proposto por Vigotski [20,21, 22]. A zdp é um estágio do processo de aprendizagem em que a criança consegue fazer algo em colaboração com alguém, e que não conseguiria fazer sozinha. Em outras palavras, a zdp é a diferença entre o nível de desenvolvimento atual, cujas funções mentais já estão maduras, e o nível de desenvolvimento intelectual, cujas funções estão em maturação. Em colaboração com outra pessoa, a criança resolve mais facilmente tarefas situadas mais próximas do nível de seu desenvolvimento. Portanto, a criança não será capaz de "imitar" qualquer tarefa, mas somente aquelas que se encontram na zona das suas próprias potencialidades intelectuais. Em colaboração, a criança se revela mais forte e mais inteligente que trabalhando sozinha, projeta-se ao nível das dificuldades intelectuais que ela resolve, mas sempre existe uma distância rigorosamente determinada por lei que condiciona a divergência entre a sua inteligência ocupada no trabalho que ela realiza sozinha e a sua inteligência em colaboração [20: 329]. Quando Vigotski discorre sobre a zdp, seu foco está dirigido para o papel que a instrução ocupa em capacitar a criança para se apropriar dos conceitos cientí- ficos, que são vistos como ferramentas psicológicas que medeiam as funções mentais superiores [23: 317].

Embora Vigotski tenha enfatizado a influência decisiva da instrução durante o processo de desenvolvimento, ele não tratou a natureza da instrução em si como uma problemática, isto é, não qualificou o que é uma instrução boa ou ruim, ou quais atividades educacionais são mais ou menos relevantes no processo de ensino-aprendizagem em cada faixa etária. É nesse ponto que Wells [23: 318] sugere uma abordagem que enfatize a importância de atividades significativas e relevantes para os estudantes no momento em que nelas se engajem, sugerindo a criação de comunidades de aprendizagem onde prevaleça o questionamento dialógico. Wells [23] amplia o conceito de zdp, entendendo que ela é criada na interação entre o estudante e os co-participantes em uma atividade, incluindo as ferramentas disponíveis e as práticas selecionadas, e isso depende tanto da natureza e da qualidade daquelas interações, quanto do limite da capacidade do aprendiz [23: 318]. Nesse sentido, a zdp emerge na atividade e nas formas como os co-participantes resolvem problemas e constroem soluções. Como uma oportunidade para aprender com e de outros, a zdp aplica-se a todos os participantes e não só aos menos habilidosos ou mais imaturos, por isso tem lugar ao longo de toda a vida [23: 331].

$\mathrm{O}$ autor conclui que a aprendizagem na zdp envolve todos os aspectos do aprendiz, agir, pensar e sentir; e isso muda não só suas possibilidades de participação em uma atividade, como também a sua identidade. Porque os mundos individual e social são mutuamente constitutivos, a transformação do estudante também envolve a transformação das comunidades de aprendizagem nas quais ele esteja inserido. Dessa forma, a relação dialética entre indivíduo e sociedade - de criar e ser criado por; a mediação da ação por ferramentas e práticas materiais e semióticas; os múltiplos níveis nos quais o desenvolvimento prévio capacita e impulsiona as ações e interações; e a atividade como o lugar no qual estes fios são tecidos, como as fontes do passado são organizadas no presente para construir o enfrentamento do futuro - envolve transformação. Todavia, essa transformação tem várias possibilidades, pois o desenvolvimento pode tomar várias direções. Ao professor cabe tornar disponível um legado do passado, e apoiar e guiar seus estudantes para a criação de suas próprias alternativas para o futuro [23: 332].

\section{Problematização e dialogia: estraté- gias para o diálogo a distância}

Pode-se considerar, a partir das ideias expostas até aqui, que uma interessante estratégia para o diálogo em $\mathrm{EaD}$, converge na direção de se conduzir o estudante para 
a problematização [10]. Problematização é aqui entendida como domínio e apropriação [25] de conhecimento por meio da dialogia. Esse tema tem sido objeto de estudo em muitas pesquisas. Parte desses estudos foi inspirada na obra de Freire [11, 12], que aponta para o fato de que estudar não é um ato de consumir ideias, mas de criá-las e recriá-las [11:12], por meio de um diálogo que favoreça a recodificação de significados, isto é, a problematização. $\mathrm{O}$ autor sugere a educação dialógica como fomentadora da problematização e da co-laboração. Para ele, problematizar é exercer uma análise crítica sobre a realidade problema [13: 97]. Isso significa a necessária coparticipação dos sujeitos no ato de elaboração de sínteses para reelaboração de conceitos.

Os estudos de Mion e Angotti [18] definem a problematização como sendo uma ação para a mudança, um "fazer diferente", de modo a permitir que os envolvidos em uma dada situação de aprendizagem, os estudantes, levantem os problemas observados, apontem situações-limites, as anomalias, os erros conceituais, questionem conceitos e estratégias metodológicas utilizadas. A problematização é o oposto da exposição e exige que o ato educativo organize-se em quatro momentos: planejamento, ação, observação e reflexão. Também Berbel $[5,6]$, ao desenvolver a proposta de uma metodologia da problematização, definea como sendo o processo de o ser humano tomar consciência de seu mundo e atuar intencionalmente para transformá-lo, sempre para melhor, para um mundo e uma sociedade que permitam uma vida mais digna para o próprio homem. Segundo a autora, seguir esta metodologia significa fazer a observação de uma situação real, definir um problema, questionar suas causas e determinantes, teorizar, analisar e chegar a uma nova ação. A aprendizagem que acontece nesse caminho irá permitir uma associação e uma superação dos conhecimentos por conta do envolvimento que o estudante tem [6:15].

Portanto, a problematização é um dos pressupostos da aprendizagem dialógica, e é entendida como estratégia para condução da aprendizagem a partir do estímulo à reestruturação de problemas e elaboração de sínteses que levem à apropriação de conhecimento (Dotta, 2009). Sob o alicerce das concepções teóricas que orientam este trabalho, problematizar significa apropriar-se do discurso do outro para construir novos significados [10]. Na medida em que o sujeito recria, reinterpreta, reconstrói a ideia alheia, para torná-la própria e significativa, ele está se apropriando dos significados. Como descreveu Wertsch [25: 93], a apropriação é o processo de adotar algo para si, como se fosse próprio. Quando nos apropriamos de uma ideia, o fazemos gerando uma versão pessoal, reproduzindo-a com a nossa própria voz. Quando há problematização, ao se apropriar de uma ideia, além da capacidade de o indivíduo desenvolver estratégias próprias para selecionar e analisar informações, organizar procedimentos de investigação, questionar as informações encontradas, extraindo dados com o propósito de solucionar problemas propostos em sala de aula ou a partir de uma interação, ele também é capaz de recontextualizá-la, podendo conceber outros campos de aplicação dessa mesma ideia, outros cenários, que não só aqueles de uma situação de ensino, mas também para a solução de problemas autênticos, vividos ou imaginados por ele [10]..

Então a problematização se dá pelo diálogo, que é fundador e fomentador da negociação de significados entre os interlocutores para que se realize a compreensão [10], por isso em um diálogo problematizador, a transmissãorecepção de informações dá lugar à reelaboração de significados por meio do questionamento e da construção colaborativa de significados. Para que isso ocorra no diálogo a distância, é necessário que tutores conheçam o processo de organização de ideias dos estudantes, isto é, o contexto em que um problema surgiu.

Segundo Bakhtin [1], é o contexto extraverbal que torna uma palavra plena de significado. Este contexto extraverbal compreende três fatores: i) o horizonte espacial comum dos interlocutores, a unidade do visível; ii) o conhecimento e a compreensão comum da situação por parte dos interlocutores; e iii) sua avaliação comum dessa situação [1: 5]. Em uma atividade de tutoria a distância em que o diálogo ocorre principalmente por meio da escrita, esse processo se dá em seu plano interno. O tutor inicialmente compartilha, com o estudante, do sistema de signos, mas não, necessariamente, do processo de organização de suas ideias. Por essa razão, para que ele possa gerir um diálogo problematizador, sua primeira atitude deve ser a de identificar a origem das questões enviadas pelo estudante, acessar seus conhecimentos prévios, entender suas necessidades, conhecer o contexto extraverbal motivador das suas dúvidas, para poder auxiliá-lo a construir suas próprias respostas. Como consequência, a elaboração de suas mensagens deve se dar por meio de um questionamento ao estudante sobre o que o levou a formular suas dúvidas, que conhecimentos ele já tem sobre o tema, enfim, qual foi o contexto em que o problema surgiu. O compartilhar desse contexto deverá possibilitar o encaminhamento de um diálogo problematizador.

Outro fator a se considerar para a prática do diálogo a distância, entre um tutor e um estudante, é o fato de que muito provavelmente esses sujeitos não se conhecem pessoalmente, portanto, não têm estabelecido entre si vínculos sociais até o início de um curso, ou têm vínculos de natureza fraca. Portanto, espera-se que ao longo do tempo, esses vínculos possam se fortalecer, na medida em que o curso avança e os fluxos de diálogo aumentem. Para isso, cabe ao tutor, buscar o engajamento do estudante, iniciando o processo de construção de empatia, para, então, conduzir à problematização e à aprendiza- 
gem. Isso irá requerer o uso de uma linguagem apropriada à comunicação a distância.

Na comunicação a distância, ocorre uma reformulação dos sistemas linguísticos, como observa Baron [4], ao estudar a linguagem do correio eletrônico e verificar que ela apresenta características da linguagem escrita e da linguagem falada, sugerindo então a ocorrência de uma linguagem híbrida nesse meio. Crystal [9] revela que várias propriedades dessa comunicação - como, por exemplo, simultaneidade, isto é, poder estar disponível em um sem-número de computadores; fluidez, possibilidade de cópia e alteração em seu conteúdo, que transcendem as limitações de outros textos - têm consequências para a caracterização da linguagem, e essas, combinadas com aquelas associadas à fala e à escrita, tornam a linguagem da internet um genuíno "terceiro meio", portanto, um novo sistema linguístico. Essas características também foram observadas por Freitas [14] Segundo a autora, uma nova forma de escrita está se criando no meio virtual. É toda uma escrita carregada de oralidade. A interface oralidade/escrita parece se dissolver no ciberespaço. Os enunciados construídos não apresentam fronteiras nítidas misturando forma, processos e funções da oralidade e da escrita [14: 15].

Barboza [8] sugere a reformulação da escrita em ambientes virtuais de aprendizagem, de modo que o aspecto afetivo seja valorizado na comunicação e motive o estudante a participar do diálogo. O estímulo ao engajamento do estudante dá-se pela mediação emocional [8], na qual o tutor privilegia o aspecto motivacional do estudante e a criação de vínculos afetivos entre os sujeitos do diálogo. Segundo a autora, a aprendizagem pode se tornar então mais significativa quando o tutor se relaciona com os estudantes de modo afetivo. Para isto é importante o contato mais direto com o estudante, chamando-o pelo nome, e abordando assuntos que são do interesse deste, de modo que se tenha um maior envolvimento entre os sujeitos [8: 24]. A autora se refere ao uso da escrita sensível, um modo de escrever que resgata o âmbito subjetivo e pessoal do diálogo escrito, por meio da valorização das saudações, do uso de adjetivos positivos, da identificação das características emocionais dos indivíduos que estabelecem o diálogo. Trata-se de uma linguagem não formalizada, espontânea, subjetiva, que motiva o estudante a participar do diálogo, fomentando os vínculos interpessoais [15].

Muitas vezes, os agentes de uma interação são levados a lançar mão do uso de onomatopéias ou criar novos signos para representar o que seria sua expressão verbal face a face. Barboza e Giordan [7] observaram que quando um tutor se utiliza da escrita sensível ele consegue promover o retorno do estudante para o diálogo. Dotta [10] constatou que esse tipo de escrita favorece o estabelecimento da empatia. A atitude do tutor, ao utilizar a escrita sensível, cumprimentando os estudantes em todas as mensagens, tratando-os pelo primeiro nome, falando um pouco de si, valorizando as perguntas e as ideias dos estudantes, motivando-os por meio de questionamentos, tentando acessar seus conhecimentos prévios, contribuíram para seu engajamento e para prosseguir com a interação. A continuidade do diálogo prepara o contexto para a problematização.

Inúmeras são as formas possíveis de se conquistar o engajamento do estudante em um curso: compartilhar o contexto extraverbal, estabelecer empatia, lançar mão da função dialógica do discurso, de forma a fomentar a problematização. A seleção de uma ou outra estratégia pode inclusive depender das características das mensagens formuladas pelos próprios estudantes. $\mathrm{Na}$ proposta de Wells [23], esse compartilhar se dá pela co-construção de conhecimento por professores e estudantes em atividades realizadas em parceria, e será a natureza dialógica do discurso que irá proporcionar essa construção. A empatia entre os interlocutores em interações a distância pode ser promovida pela função dialógica do discurso e pelo uso de diferentes gêneros discursivos, estilos composicionais e linguagens que facilitem a construção, pelos agentes de uma interação, de uma imagem de seu destinatário, ou, como sugeriu Lotman [16], a construção de uma memória comum entre os interlocutores.

A seguir, a título de exemplo, são analisados alguns trechos de interação ocorridos em um serviço de tutoria oferecido a estudantes de Ensino Médio, no ano de $2007^{1 .}$ A análise desses trechos serve para demarcar as estratégias utilizadas por uma tutora para estabelecer empatia com o estudante, buscando seu engajamento e levando-o à problematização. Também serão discutidas algumas estratégias utilizadas pela mesma tutora de modo a promover a aprendizagem dialógica. É importante destacar que essas estratégias não esgotam o assunto, mas podem servir de inspiração para as necessárias reflexões que tutores precisam fazer durante sua atuação.

Quadro 1. Trecho de interação 1 entre uma tutora e um estudante \begin{tabular}{|l|}
\hline (...) \\
\hline $\begin{array}{l}\text { Data: 13/11/2007 - 21:15:16 | Mensagem Enviada } \\
\text { por: Tutora 7A }\end{array}$ \\
\hline $\begin{array}{l}\text { (...) Aliás, muito interessante sua dúvida, só } \\
\text { lhe peço para fazer umas perguntinhas, antes de }\end{array}$ \\
\hline
\end{tabular}

\footnotetext{
${ }^{1}$ Esse serviço foi implementado em uma disciplina de Metodologia de Ensino, oferecida a distância por uma universidade pública de São Paulo. Os estudantes dessa disciplina cumpriram estágio supervisionado, oferecendo tutoria pela internet para estudantes do Ensino Médio. Nessa atividade sua principal responsabilidade era responder a dúvidas dos estudantes. utilizando o software Tutor em Rede. Um estudo detalhado sobre o serviço pode ser obtido em [***omitido para revisão**].
} 


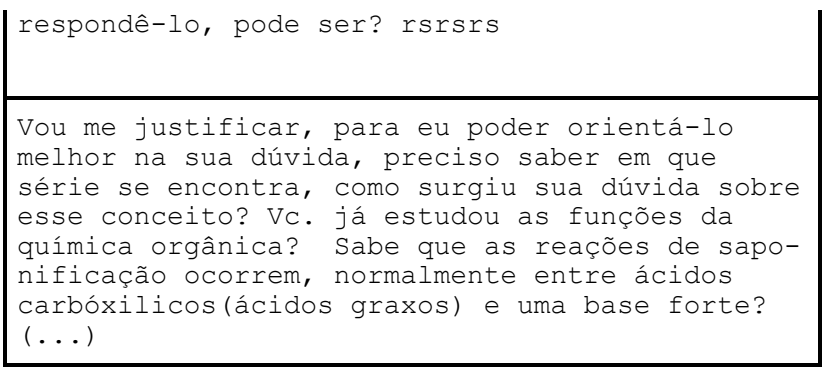

Como se pode observar no trecho de interação do Quadro 1, uma das marcas das enunciações dessa tutora é a oralidade. Nota-se, também, que ela lança mão da escrita sensível, valorizando a pergunta enviada pelo estudante. O trecho “(...) Aliás, muito interessante sua dúvida..." mostra uma das maneiras que ela tenta estabelecer empatia com o estudante, na medida em que atribui importância à mensagem enviada e emite adjetivos positivos. Além disso, ela procura acessar os conhecimentos prévios do estudante, questionando-o objetivamente "como surgiu sua dúvida sobre esse conceito?”. Dessa maneira, a tutora está tentando conhecer o processo de organização das ideias do estudante, saber em que série o estudante se encontra pode auxiliá-la a delinear o contexto extraverbal em que a dúvida surgiu.

Em outros casos, como no trecho mostrado no Quadro 2,, além de se apresentar, revelando os próprios motivos em estar à disposição para responder às dúvidas dos estudantes, fala sobre si de modo a também deixar o estudante mais à vontade. Ela oferece ao estudante algumas informações para que ele também possa acessar o contexto extraverbal da tutora e, por meio da espontaneidade, de uma linguagem informal, coloquial, estabelecem-se os vínculos interpessoais, favorecendo a aproximação entre ambos e, ao compartilhar seu contexto e questionar o do estudante, possibilita o desenvolvimento de um fluxo de diálogo mais longo, favorecendo, portanto, a criação de um espaço para a problematização.

Quadro 2. Trecho de interação 2 entre uma tutora e um estudante

\begin{tabular}{|c|}
\hline $\begin{array}{l}\text { Calcular "delta" H }(06 / 11 / 2007-14: 11: 14- \\
\text { Estudante 131) }\end{array}$ \\
\hline $\begin{array}{l}\text { Data: 06/11/2007 - 15:49:45 | Mensagem Enviada } \\
\text { por: Tutora 7A }\end{array}$ \\
\hline $\begin{array}{l}\text { (...) Olha meu nome é Tutora } 7 \mathrm{~A} \text { e estarei tra- } \\
\text { balhando no estagio de tutoria até as primeiras } \\
\text { semanas de dezembro, moro em Goiás e gostaria } \\
\text { de saber de qual estado vc. é e qual série está } \\
\text { cursando, pode ser? Poderia me dizer o motivo } \\
\text { de estar em dúvida nessa questão Qual o con- } \\
\text { ceito de "delta" H (...) }\end{array}$ \\
\hline
\end{tabular}

Tendo estabelecido a empatia tutor-estudante, e alcançado o engajamento dos estudantes, a atividade do tutor prossegue no sentido de levar o estudante à problematização dos conteúdos, e concretizar a aprendizagem, sempre buscando atender às expectativas dos estudantes, ampliar o fluxo dos diálogos e, ao mesmo tempo, experimentar estratégias para motivá-los a buscar caminhos próprios para construção de suas respostas, tentando problematizar suas dúvidas. Uma alternativa, seguindo a concepção de questionamento dialógico proposto por Wells [23], e observado por Dotta [10], é a instauração de um jogo de perguntas e repostas que tem por intuito levar os estudantes a se apropriar dos conceitos abordados nos diálogos.

Esse jogo é iniciado pelo tutor com a formulação de perguntas relacionadas ao tema de uma mensagem inicial enviada pelo estudante, cujas respostas dadas por ele podem levá-lo a formular novas perguntas para o tutor, que, por sua vez, ao responder, acrescenta novas perguntas e assim sucessivamente. A construção do discurso do tutor considera a atitude responsiva do interlocutor [1], e, para isso, cabe ao tutor acessar o horizonte conceitual do estudante de modo a conseguir sua adesão ao jogo de perguntas e respostas. Essa estratégia pressupõe alguma autonomia do estudante, uma vez que não serão dadas, às suas perguntas, respostas prontas, mas, sim, a indicação de caminhos - de pesquisa, por exemplo - para formular sua própria resposta. Com essa estratégia, além de ampliar o fluxo do diálogo, o tutor fomenta a construção das respostas pelo estudante. O Quadro 3 apresenta algumas dessas características.

Quadro 3. Trecho de interação 3 entre uma tutora e um estudante Gelo seco (27/10/2007 - 20:10:14 - Estudante 128)

Data: 27/10/2007 - 20:36:14 | Mensagem Enviada por: Estudante 128

Por que sai fumaça do gelo seco??

Data: 28/10/2007 - 13:51:40 | Mensagem Enviada por: Tutora $7 \mathrm{~A}$

Oi, Estudante 228! Que bom vc. apresentar prá gente a sua dúvida! (...) Gostaria para poder oreintá-lo melhor que me falasse um pouco de vc., o que faz e de onde surgiu essa questão que nos coloca, pode ser? Fale também da urgência com que necessita da resposta para eu poder ver como poderemos trabalhar na elaboração dos conceitos para entender essa questão...

Sobre o que nos perguntou, gostaria de levantar as seguintes questões:

- Sabe qual a composição do gelo seco?

- E o conceito de sublimação?

- Saber como a pressão pode influenciar o estado físico das substâncias pode lhe ajudar a entender o porquê da fumaça... (...)

Data: 28/10/2007 - 18:24:27 | Mensagem Enviada por: Estudante 128

Olá Tutora 7A! (...) 
Essa questão me surgiu repentinamente, quando vi um colega meu falar de gelo seco. Procurei agora na internet e vi que a composição do gelo seco é de dióxido de carbono solidificado, o que foi uma surpresa pra mim... é isso mesmo??? Quando você mencionou sublimação eu matei a charada! É verdade, nem sei como não associei, - gelo seco passa do sólido direto para o gasoso né?? Só não sei como a pressão pode influenciar o estado físico das substâncias.... $(\ldots)$

Data: 28/10/2007 - 22:16:44 | Mensagem Enviada por: Tutora $7 \mathrm{~A}$

Boa noite, Estudante 128!

Nossa que bom ter retornado e já com as respostas as suas questões, isso mesmo o gelo seco é formado por dióxido de carbono (...) agora a palavra seco vem do fato de sofrer sublimação (...) Agora a questão da pressão tem haver com - estado físico das substâncias (...) Já imaginou como é feito o gelo seco? (...)

Observa-se nesse trecho (no Quadro 3) que a tutora prossegue com a escrita sensível e, a fim de conhecer o horizonte conceitual do estudante, convida-o a falar sobre si e a explicar a origem de sua dúvida, entendendo que dessa forma poderá obter informações sobre seus conhecimentos prévios e assim selecionar melhores estratégias para conduzir a questão, como ela mesma afirma: “(...) para eu poder ver como poderemos trabalhar na elaboração dos conceitos para entender essa questão...”. A partir daí, ela elabora um conjunto de perguntas abordando os temas relacionados à dúvida do estudante, instaurando o jogo de perguntas e respostas. Dessa maneira, em vez de oferecer uma resposta pronta, a tutora elenca uma série "pistas" que o estudante deverá seguir para elaborar sua resposta.

O estudante explica que sua dúvida surgiu de um comentário feito por um amigo, e, para responder à pergunta feita pela tutora, "Sabe qual a composição do gelo seco?", afirma ter pesquisado na internet e descoberto que ele é composto de dióxido de carbono solidificado, informação que o surpreendeu a ponto de pedir confirmação à tutora, “(...) é isso mesmo???”. Em seguida, ao dizer "Quando você mencionou sublimação eu matei a charada!", percebe-se que o jogo de perguntas e respostas iniciado pela tutora foi bem-sucedido, tanto que o estudante comenta sobre a sublimação, revelando alguma surpresa consigo mesmo por não ter feito a associação da passagem do estado sólido para o gasoso, antes que a tutora lhe perguntasse sobre o assunto. Finalmente, o estudante afirma desconhecer “(...) como a pressão pode influenciar o estado físico das substâncias....", ficando com esta dúvida agradece à ajuda e se despede.

A tutora responde no mesmo dia elogiando o fato de o estudante já ter construído suas respostas, acrescenta algumas informações sobre o gelo seco e passa a explicar a relação da pressão com o estado físico das substâncias.
Em seguida a tutora questiona “(...) Já imaginou como é feito o gelo seco? (...)", prosseguindo assim com o jogo de perguntas e respostas.

Em outros episódios de interação desse estudante1, podese observar que ele atualiza o estilo composicional utilizado pela tutora, de elaboração de perguntas, toma a iniciativa de organizar os subtemas das questões, enumerando as cadeias enunciativas, transcrevendo cada uma das perguntas enviadas pela tutora, aceitando participar do jogo de perguntas e respostas. Após a transcrição de cada pergunta, ele inicia uma reflexão para tentar respondê-las, aceitando, assim, aderindo ao iniciado pela tutora, pois, segundo ele mesmo, isso pode contribuir para construir sua resposta. Também é possível perceber sua autonomia para o estudo e a pesquisa sobre os temas de suas dúvidas. Os resultados de seus estudos levam-no a problematizar as perguntas colocadas pela tutora, construindo reflexões sobre aqueles questionamentos, seu conhecimento prévio, os estudos realizados e suas novas perguntas. Tanto que ele mesmo percebe que para construir suas respostas ele precisa esclarecer novas dúvidas, como se pode observar no seguinte trecho: "se você me responder essa acho que consigo responder o que você me perguntou...".

\section{Considerações finais}

O jogo de perguntas e respostas iniciado pelo tutor, quando tem a adesão do estudante, que também cria perguntas, estabelece uma tensão entre a colaboração/competição entre ambos, e promove a problematização, de modo que as perguntas e as respostas têm a função de reestruturar os problemas, indiciando que o papel de um tutor não é fornecer respostas prontas, mas, sim, orientar o estudante a construir suas próprias respostas. Saber dos conhecimentos prévios dos estudantes é fator primordial para que esse jogo atenda aos objetivos do tutor. Quando o estudante não fornece informações sobre aquilo que conhece e, ainda, tem apenas o objetivo prático de resolver um problema escolar, o tutor pode não conseguir levá-lo a problematizar uma dúvida enviada. Em casos em que o estudante não "aceite" participar do jogo, ou não entenda a proposta do tutor, este deve insistir, demonstrando convicção de sua postura de orientação, cujas perguntas servem como estratégia para condução dos estudantes, e é, portanto, a mais adequada. Isso, porque o papel do tutor é conduzir a aprendizagem e não apenas entregar informações.

A não adesão de um estudante ao jogo pode ocorrer devido ao fato de um estudante estar preocupado em cumprir

\footnotetext{
${ }^{1}$ Esse estudante iniciou 21 interações com essa tutora. As análises de outras interações podem ser consultadas em [**omitido para revisão**].
} 
com urgência sua tarefa, e por isso não "compra" a ideia de participar. Em um primeiro momento, pode-se inferir que o tempo pode ser um obstáculo para o debate entre o tutor e o estudante. Estudantes que têm urgência em obter suas respostas não se dispõem em participar de um jogo de perguntas e respostas. Todavia, pode ocorrer de uma dúvida que um estudante tem a responder não se encontra em sua zona de desenvolvimento proximal [10], e a resposta do tutor pode estar distante da zona das potencialidades intelectuais do estudante. Os enunciados do tutor podem ser divergentes dos conhecimentos prévios do estudante. Como sugere Wells [23], a zona de desenvolvimento proximal é criada na interação entre o estudante e os co-participantes em uma atividade, incluindo as ferramentas disponíveis e as práticas selecionadas, e isso depende tanto da natureza e da qualidade daquelas interações, quanto do limite da capacidade do aprendiz. O tutor, irredutível em seu objetivo de adotar uma postura de orientação, acaba por não conseguir conhecer o horizonte conceitual do estudante, se este não se render aos seus questionamentos.

O jogo de perguntas e respostas deve servir de estímulo para os estudantes reelaborarem suas questões, realizarem pesquisas, e construírem suas próprias respostas, adotando ora o estilo composicional, ora o gênero de discurso, sugeridos pelo tutor, e, como consequência, apropriar-se dos conceitos a serem aprendidos. Para tanto, deve haver a presença da dialogia, não só entre o tutor e os estudantes, mas também entre os conhecimentos escolares, páginas de internet, livros, experiências pessoais, diferentes gêneros de discurso etc. Nesse jogo, o tutor assume uma postura de parceria com os estudantes e atua em uma relação de baixa simetria, construindo, junto com eles, o caminho para as respostas. A redução da assimetria entre tutor e estudantes, no entanto, não anula totalmente a posição do tutor. O que ocorre é a disputa pelo controle da interação e a negociação de significados, de modo a levar à problematização.

O uso da escrita sensível auxilia para o estabelecimento da empatia entre o tutor e o estudante e, dessa forma, se ampliar o fluxo de um diálogo a distância. O jogo de perguntas e respostas é fomentador da aprendizagem dialógica desde que, em uma interação, o tutor seja capaz de atrair o estudante para o diálogo problematizador. Para tanto, o tutor deve assumir uma postura de parceria, colaborativa, com o estudante que esteja atendendo. Ainda assim, observam-se alguns obstáculos para a aplicação dessas estratégias: nem sempre o motivo do estudante é condizente com o do tutor, gerando uma disputa de motivos a serem tratados no diálogo e dificultando a aprendizagem. Nem por isso se deve descartar essa proposta, pois a prevalência da dialogia nos discursos do tutor e a estratégia de conduzir jogos de perguntas e respostas para realização dos diálogos mostraram-se estratégias eficazes e fundamentais para a problematização das dúvidas dos estudantes.

Em casos em que essa estratégia não seja bem-sucedida, poder-se-ia intentar alternativas para minimizar os problemas da condução do diálogo em $\mathrm{EaD}$ : de um lado, o desenvolvimento de ambientes virtuais que favoreçam a dialogia, de outro, levar os tutores a desenvolverem análises críticas sobre seu papel, e por fim, criar estratégias que possam conduzir os estudantes à elaboração de sínteses a partir da reestruturação dos problemas.

Por fim, cabe ao tutor buscar conhecer os estudantes atendidos e a origem de suas dúvidas, mas ainda é premente a necessidade de se realizar investigações que tragam à luz o processo de formação da autonomia, uma vez que, como este trabalho revelou, a autonomia é elemento fundamental para a aprendizagem ao longo do diálogo a distância.

\section{Agradecimentos}

Agradece-se à FAPESP - Fundação de Amparo à Pesquisa do Estado de São Paulo pela bolsa de doutorado concedida para desenvolvimento da pesquisa que possibilitou gerar este artigo.

\section{Referências}

[1] M. (Volochinov) Bakhtin. Estética da criação verbal. São Paulo, Martins Fontes, 2003.

[2] M. (Volochinov) Bakhtin. Marxismo e filosofia da linguagem. São Paulo, Hucitec, 2004.

[3] M. (Volochinov) Bakhtin. Problemas da poética de Dostoiévski. Rio de Janeiro, Forense Universitária, 2005.

[4] N. S. Baron. Letters by phone or speech by other means: the linguistics of email. Language and Communication 18, p. 133-170, 1998.

[5] N. A. N. Berbel. "Problematization" and problem-based learning: different words or different ways? Interface: Comunicação, Saúde, Educação, 2(2): 139-154, 1998.

[6] N. A. N. Berbel. Metodologia da problematização. Londrina, Eduel, 2006. 196 p.

[7] L. C. Barboza, M. Giordan. Análise de interações em um sistema de tutorial. Anais do Virtual Educa 2007. São José dos Campos, Univap, 2007.

[8] L. C. Barboza, M. Giordan. Práticas discursivas em ambientes virtuais de aprendizagem. Caderno de Resumos do II Seminário Internacional de 
Lingüística. p. 65. São Paulo, Unicsul, 2007.

[9] D. Crystal. Language and the Internet. Cambridge, Cambridge University Press, 2001.

[10] S. Dotta. Aprendizagem dialógica em serviços de tutoria pela internet: Estudo de caso de uma tutora em formação em uma disciplina a distância. Tese de doutorado. FEUSP, São Paulo, 2009.

[11] P. Freire. . Ação cultural para a liberdade. Rio de Janeiro, Paz e Terra, 2007. 176 p.

[12] P. Freire. Pedagogia do oprimido. $45^{\mathrm{a}}$ ed. Rio de Janeiro, Paz e Terra, 2005. 216 p.

[13] P. Freire. Extensão ou comunicação? Rio de Janeiro, Paz e Terra, 1977. 96 p.

[14] M. T. F. Freitas. Escrita teclada: uma nova forma de escrever? Anais da $23^{a}$ Reunião da Anped. Caxambu, 2000. Disponível em http://www.anped.org.br/reunioes/23/textos/1011 t.PDF. Acessoo em 2/2/2006.

[15] D. Haetinger, M. G. Haetinger. Escrita Sensível: uma proposta de mediação emocional. Renote Revista Novas Tecnologias na Educação. Porto Alegre, Cinted/UFRGS, março, 2004. Disponível em: http://www.cinted.ufrgs.br/renote/ mar2004/artigos/escrita_sensivel.pdf. Acesso em: 29/08/2008.

[16] Y. M. Lotman. The text and the structure of Its audience. New Literary History. 14(1), Problems of Literary Theory, pp. 81-87, 1982.

[17] L. D. Machado, E. C. Machado. O papel da tutoria em ambientes de EaD. Anais do XI Congresso Internacional de EaD. Salvador, 2004.

[18] R. A, Mion, J. A. P. Angotti. A reconstrução racional e a prática educacional em Fisica. Anais do VIII Encontro de Pesquisa em Ensino de Física. Águas de Lindóia, Sociedade Brasileira de Física, 2002.

[19] M. Silva. Sala de aula interativa. Rio de Janeiro, Quarter, 2000. 232 p.

[20] L. S. Vigotski. A construção do pensamento e da linguagem. São Paulo, Martins Fontes, 2001. 500 p.

[21] L. S. Vigotski. A formação social da mente. São Paulo, Martins Fontes, 2003. 192 p.

[22] L. S. Vigotski. Teoria e método em psicologia. São Paulo, Martins Fontes, 2004. 524p.

[23] G. Wells. Dialogic inquiry: toward a sociocultur- al pratice and theory of education. Cambridge, UK, Cambridge University Press, 1999. 372 p.

[24] J. V. Wertsch, A. L. B. Smolka. Continuando o diálogo: Vigotski, Bakhtin e Lotman. In: DANIELS, Harry (org.). Vygotsky em foco: Pressupostos e desdobramentos. Campinas, Papirus, 1994. $296 \mathrm{p}$.

[25] J. V. Wertsch. La mente en acción. Madrid, Aíque, 1999. 304 p. 